\title{
Knowledge Management through Organizational Culture Change
}

\author{
Oleg Tilchin ${ }^{1} \&$ Mohammad Essawi ${ }^{2}$ \\ ${ }^{1}$ Computer Sciences Department, Academic College of Education, Israel \\ ${ }^{2}$ Academic College of Education Al-Qasemi, Israel \\ Correspondence: Oleg Tilchin, Professor, Computer Sciences Department, Academic College of Education, Israel. \\ E-mail: otilchyn@yahoo.com
}

Received: July 26, 2013

doi:10.5430/ijba.v4n5p24
Accepted: August 15, 2013

Online Published: September 6, 2013

URL: http://dx.doi.org/10.5430/ijba.v4n5p24

\begin{abstract}
A dynamic model serving as a tool for implementation of experiences of organizational culture change is suggested. It is aimed at providing effective knowledge management (KM) of employees. Dynamics of the model are expressed by a change of its parameters. It is adjusted to the dynamic process of implementing experiences. Building the model includes elaboration and integration of interconnected components. The "Result" is a central component of the model. This component determines a desired organizational goal and possible directions of its attainment. The "Confront" component engenders constructive confrontation in an organization. For this reason, the employees are prompted toward KM culture change with the purpose of attaining the desired result. The "Assess" component realizes complex assessments of employee proposals by management and peers in order to obtain the desired result. The "Reward" component sets the order of assigning rewards to employees based on the assessments of their proposals directed towards attaining the desired result in an organization.
\end{abstract}

Keywords: knowledge management, organizational culture change

\section{Introduction}

Organizational development and change in the modern knowledge-based economy require effective knowledge management (KM) of employees. KM can be defined as a systematically and organizationally specified process of sharing, transferring, creating, using, and saving the knowledge of employees to enhance organizational performance (Nonaka \& Takeuchi, 1995; Davenport \& Prusak, 2000; Dalker, 2011). KM is aimed at providing the right knowledge to the right people at the right time in order to improve organizational performance (O'Dell \& Hubert, 2011). KM should allow for creating organizational knowledge. It is new knowledge created by groups of employees from different subunits of the organization (Hislop, 2009). It is necessary to take into account the possibility that competition among employees may interfere with the creation and sharing of organizational knowledge.

Two types of employee knowledge are defined: explicit and tacit (Nonaka 1994; Botha et al., 2008). Explicit knowledge can be found in documents (Wellman, 2009). Tacit knowledge is experience-based knowledge embodied in people (Sternberg \& Horvath, 1999). The most valuable knowledge is tacit knowledge (Hislop, 2009; Dalker, 2011). This type of knowledge promotes organizational innovations and sustains competitive advantage (Gamble \& Blackwell, 2001; Wellman, 2009). Tacit knowledge includes mental models, expertise, cultural beliefs, and values (Botha, et al, 2008). However, management of tacit knowledge is extremely problematic. Since knowledge is inseparable from organizational culture, KM culture that induces employees' willingness to create, transfer, share, and use knowledge can promote the handling of tacit knowledge (Nonaka, Takeuchi, Umemoto, 1996; Goodman, 2006; Serrat, 2012).

Attaining desired results in an organization requires changing its culture, which determines the new way employees think and act (Connors \& Smith, 2011; Sambedna, Chandan \& Kumar, 2011). Organizational culture change is accomplished when the new results that have to be achieved by an organization are stated, actions of the employees providing attainment of the results are determined, the new organizational values guiding actions of employees are identified, and the experiences which inspire the new organizational values are formed. In short, experiences inspire values, values influence actions, and actions produce results (Connors \& Smith, 2011). An experience determines some new situation in an organization (Endsley \& Garland, 2000). 
According to the above, effective $\mathrm{KM}$ in an organization can be attained through a corresponding change of organizational culture. Use of the necessary experiences is the basis of organizational culture change. The experiences induce and promote adoption of the KM organizational values by employees. Therefore, the need to implement suitable experiences of KM organizational culture change becomes crucial. The proper tools are needed to implement the required experiences of KM culture. A model shaping the process of implementing the experiences could serve as one of the tools. Therefore, the goal of this paper is to develop the model for implementation of the experiences of organizational culture change that would ensure effective KM of employees.

\section{Literature Review}

Research leading to the attainment of the aforementioned goal of this paper is examined. It involves: influence of organizational culture on KM; creation of effective KM organizational culture; organizational culture change.

Zheng, Yang \& McLean (2009) specify knowledge as an outcome of organizational culture because knowledge is created and used in accordance with cultural values embedded in structural relationships. Wellman (2009) describes leadership roles that can facilitate organizational culture change in providing effective KM. Bukowitz \& Williams (1999), and Gamble \& Blackwell (2001) emphasize the importance of an organizational culture's promoting willingness of its employees to share their knowledge that allows the transfer and creation of knowledge. Davenport \& Prusak (2000) affirm that reciprocity is a factor affecting knowledge sharing willingness. Adel et al. (2007) examine the role of such factors as interpersonal trust, communication among employees, information systems, rewards, and organization structure in providing successful knowledge sharing.

Park \& Schulte (2004) identify and rank the most critical organizational culture attributes that promote knowledge sharing and establish a correlation between these attributes and the successful implementation of knowledge management in an organization. Gupta (2007) explores the most significant individual values and organizational cultural values promoting knowledge sharing among employees. As a result of his exploration, the author discovered that trust and collaboration, as well as openness and collaboration are individual and organizational cultural values, accordingly, which contribute to knowledge sharing.

Hislop (2009) represents an approach to the facilitation of KM through culture management and human resource management practices including performance appraisal and rewarding employees. The author examines the influence of interdependence of tacit knowledge and innovation dynamics on knowledge creation. Westover (2011) describes leadership practices and methods for creating organizational culture to promote innovations for driving organizational effectiveness.

O’Dell \& Hubert (2011) represent building of a knowledge sharing culture as an important part of their strategy for making KM successful. The authors affirm that recognition is needed for engaging employees. Pasher \& Ronen (2011) affirm that successful knowledge creation and knowledge sharing in an organization are a result of a management style based on shared values of organizational culture. These values are trust, innovation, and respect for the knowledge of employees. The authors emphasize the necessity to encourage employees to contribute their knowledge to organizational development and suggest methods for promoting interactions in order to foster knowledge creation and knowledge sharing communities in organizations.

Rhoades, Covey \& Stepherdson (2011) described a process of changing organizational culture values involving determination of the desired values, and the development and implementation of a plan for changing employee behaviors based on these values. They assert that the most critical element of changing organizational values is helping employees adopt the behaviors corresponding to the desired values by inspiring and rewarding them.

Keyton (2011) affirms that an organizational culture emerges from the communication among employees within and across structural units of an organization. The author ascertains the role of communication in managing, and changing organizational culture, promoting creation of work experiences. Gardner (2011) suggests an approach to organizational culture change. The approach consists in introducing "anomalies" that present a reality that cannot be true under the old assumptions. As more and more anomalies are presented, employees will abandon old beliefs and will be willing to adopt new ones.

Essawi (2012) created the structured dynamic value confrontation leadership model shaping the leadership process of changing organizational culture. The model is aimed at engendering constructive confrontation between the desired organizational values and the current employee values. Connors \& Smith (2011) offer the Result Pyramid Model, shaping the culture change process for attaining desired organizational results. According to the model, experiences are a basis and provide leverage of organizational culture change since the experiences inspire beliefs, the beliefs influence actions, and actions produce the results. 
The analysis of the above publications shows that the authors do not attempt to develop a systematic approach to KM influenced by organizational culture change. The elaboration of organizational culture change process affecting KM is not offered. A constructive confrontation environment in an organization promoting adoption of the KM culture values by employees has not been created. Forming collaborative groups of employees through all levels of organizational structure aimed at knowledge sharing has not been specified. A balance between competition and collaboration among employees for promoting effective KM has not been provided. Stimulation and facilitation of the adoption of organizational culture values for employees by creating and sharing knowledge have not been realized. Recognition and rewarding of employees has not been connected with the evaluation of their contribution to organizational culture change directed toward KM. Organizational knowledge required for attaining the required result has not been revealed. Ways to implement the experiences of KM culture that would inspire the needed cultural values in employees are not presented. Therefore, there is a need for development of the productive tools of organizational culture change for effective KM. The primary tool is a model for implementation of experiences aimed at KM organizational culture change.

\section{Knowledge Management through Organizational Culture Change}

Knowledge management of employees is a constructive way to improve organizational performance. The desired organizational result can be attained through implementation of the experiences which induce and promote adoption of the new organizational culture values by employees. The experiences instill the values of KM organizational culture in employees. The experiences of KM organizational culture should satisfy the following principles: rewarding of all the employees participating in the creation and assessment of peers' proposals directed towards attaining the desired organizational result according to their roles in this process; prior familiarity of the employees with the conditions of reward; generation of constructive confrontation environment in an organization; participation of managers and staff in the assessment of the proposals. Therefore, the top priority KM problem is implementation of the suitable experiences for changing KM organizational culture.

\subsection{The Model for Implementation of Experiences}

The purpose of developing the dynamic model is to create the means of implementing the experiences of KM culture. The model serves as a framework for process of changing KM organizational culture. Development of the model includes elaboration and integration of interconnected model components. Dynamics of the model are provided by the change of its parameters and they express the dynamic process of implementing experiences. The model involves the following components: Result, Confront, Assess, and Reward.

The "Result" Component

The objective of the "Result" component is to determine and declare the possible directions and conditions to attain a desired organizational result. The "Result" is a central component integrating other components of the model, and serves as the starting point for implementation of experiences.

The procedures for the "Result" component realized by management are:

- Establishing an organizational result to be attained by an organization. Attaining the result requires effective KM of employees.

- Determining the directions to attain the desired organizational result and declaring them.

- Developing the formative conditions of rewards, aimed at inducing employees to create and share knowledge to attain the desired result.

- Providing employee awareness of the principles of rewarding

The "Confront" Component

The objective of the "Confront" component is to engender a constructive confrontation in an organization during KM culture change.

The procedures of the "Confront" component are:

- Informing the employees about the need for submitting their proposals representing the different approaches to attain the desired organizational result.

- Engendering constructive confrontation between an employee and the managers guiding the KM culture change. Such confrontation is engendered by managers offering to prepare proposals in order to attain the desired organizational result. The confrontation induces the employees to prepare their proposals. 
- Manifestation of the employee proposals in the organization. Familiarization of the employees with peer proposals.

- Engendering of constructive peer confrontation caused by familiarization with the presented proposals. The confrontation is engendered by the difference between the states of adopting the new KM cultural values by the employees. The confrontation also induces employees to critically evaluate peer proposals and choose the peers suitable for collaboration.

- Engendering of self-constructive confrontation. Such confrontation is engendered as a result of an employee's self-evaluation of his or her ability to prepare proposals to attain the desired organizational result. Self-constructive confrontation induces and drives passive employees to prepare personal proposals.

The "Assess" component

The objective of the "Assess" component is assessment of employee proposals by managers and peers.

The procedures of the "Assess" component are:

- Establishing the range of assessment in the employee proposals

- Assessment of employee proposals by managers and peers

- An employee's assessment of his wish to collaborate upon realizing the proposals, which according to his opinion are his perspective and correspond to his professional abilities

- Ranking the proposals on the basis of their weights. The weight of the proposal takes into account assessments by managers and peers, and the willingness to collaborate.

The "Reward" component

The objective of the "Reward component is to reward employees according to their assessment rank.

The procedures of the "Reward" component are

- Determining a reward for the proposal according to its weight: the proposal with higher weight gets higher reward.

- Assigning a reward to the author of a proposal and employees participating in its assessment. The major portion of the determined reward is assigned to the proposal author.

- Distributing rewards among the employees participating in the assessment of the proposal by taking into account their roles in assessment (an employee assesses the proposal, an employee wishes to collaborate in the development and realization of the proposal). The employee who participates only in assessing the proposal should receive a smaller reward.

- Calculating integral personal reward of an employee by summing his rewards as an author of a proposal, as a participant in assessment of peer proposals, and as a potential collaborator in the development and realization of peer proposals.

\subsection{Managing Implementation of Experiences}

The model has changing parameters. It allows for management of implementation of experiences directed towards the change of KM organizational culture. These parameters are: the directions for attaining the needed organizational result; the quantity of the proposals that may be submitted by an employee for each determined course; the general quantity of proposals that may be submitted by an employee; the managerial assessment of employee proposals; quantity of the proposals which may be assessed by every employee; quantity of the proposals (the development and realization of which an employee may participate); the measure of reward for a proposal; distribution of the reward between the author of the proposal and the employees who assess it; distribution of the reward among the employees based on their roles in the assessment.

The required course of action for attaining the necessary organizational result is set by management according to the revealed preferable directions for attaining the result according to existent organizational knowledge. Therefore, the lack or minimal quantity of the received proposals relative to some direction reveals its infeasibility for attaining the result because of the shortage of organizational knowledge corresponding to this course. On the other hand, the maximal quantity of the received proposals relative to some course of action characterizes the ability of an organization to attain the result through this direction due to the availability of the necessary organizational knowledge. 
Changing quantity of the proposals which may be submitted by an employee relative to each predetermined direction allows for receiving larger proposals corresponding to the directions that are the most preferable for attaining the desired result. Restricting the general quantity of the proposals which may be submitted induces an employee to prepare qualitative proposals that correspond the most to his knowledge.

Availability of management assessment in the integral assessment of employee proposals characterizes the extent of managerial influence on choosing the most productive proposals. The absence of management assessment is the evidence of absolute independence of employees in assessing proposals of their peers. Determination of the quantity of the proposals that may be assessed by every employee is aimed at adjustment of two factors: 1. employee inducement to choose for assessment only the proposals that correspond the most to their knowledge; 2. aspiration of employees to receive the maximal reward for assessment.

Change of the quantity of the proposals where an employee is allowed to collaborate with their authors in their development and implementation is caused by the need to provide a balance between the two factors: 1 . the need to intensify collaboration in the organization and 2. motivation of employees to choose the proposals where collaboration would be the most suitable in terms of their knowledge and preferences.

According to the "Reward" component of the model the reward measure of the proposal depends on its place in the assessment rank. As appears from the above, the place of the proposal is determined based on its assessment weight, which involves assessments by managers and peers, and the willingness to collaborate. However, the proposals with equal weights may get different rewards. It is caused by the aspiration to provide preferable influence of one of its parameters forming the assessment weight. Dividing the reward determined for the proposal between its author and the employees assessing it depends on the need to stimulate either preparing or assessing the proposals. The reward intended for the employees assessing proposals is divided among them by taking into account their roles in the assessment. If there is necessity to stimulate collaboration in an organization, then the greater part of the reward is presented to those wishing to collaborate.

\section{Conclusion}

A dynamic model to implementation of the experiences aimed at organizational culture change is suggested. This change is directed towards attaining desired organizational results through KM. The experiences induce, promote, and adjust adoption of the values by employees of a KM organizational culture that furthers effective performance of KM procedures. The model includes interconnected components. Dynamics of the model reflects the dynamic process of implementing experiences directed towards changing KM organizational culture. Changeability of the model's parameters provides an opportunity to manage the implementation of experiences.

The essential principles which should satisfy the experiences of KM organizational culture are formulated. These experiences ensure effective creation and sharing of knowledge in an organization, owing to: building a constructive confrontation environment promoting change of KM organizational culture; stimulation and facilitation of performance of KM procedures by employees; attainment of balance between competition and collaboration of employees; formation of collaborative groups through all levels of organizational structure; exchange of information among employees regarding their interests and preferences; revelation of tacit knowledge of employees; mutual evaluation of knowledge creation and sharing by employees; employee rewards coordinated with obtained complex assessment; determination of the knowledge - based directions for improving organizational performance.

Further research will be directed towards the exploration of the model's productivity by applying the model to the development of organizational innovations, and unification of the model for implementation of the experiences facilitating changes in organizational culture.

\section{References}

Adel, Ismail, Al-Alawi, Nayla, Yousif, Al-Marzooqi, \& Yasmeen, Fraidoon, Mohammed. (2007). Organizational Culture and Knowledge Sharing: Critical Success Factors. Journal of Knowledge Management, Emerald Group Publishing Limited, 11(2), 22-42.

Botha, A., Kourie, D., \& Snyman, R. (2008). Coping with Continuous Change in the Business Environment, Knowledge Management and Knowledge Management Technology. Chandice Publishing Ltd. http://dx.doi.org/10.1533/9781780632056

Bukowitz, W., \& Williams, R. (1999). The Knowledge Management Fieldbook. Financal Times/Prentice Hall.

Dalker, Kimiz. (2011). Knowledge Management in Theory and Practice (2 $2^{\text {nd }}$ ed.). The MIT Press. 
Davenport, T.H., \& Prusak, L. (2000). Working Knowledge: How Organizations Manage What They Know. Harvard Business School Press, Boston, MA.

Essawi, M. (2012). The Value Confrontation Leadership Model. International Leadership Journal, 4(2), 72-82.

Gamble, P.R., \& Blackwell, J. (2001). Knowledge Management: A State of the Art Guide. Kogan Page Ltd.

Gardner, J. R. (2011). Changing and Organizational Culture. Cognitive Behaviour. Retrieved from www.cognitivebehavior.com/management/concepts/changing_org_culture.html

Goodman, Joanna. (2006). Developing a KM Culture. Ark Group.

Gupta, Bindu. (2007). Role of Individual Values and Organizational Cultural Values in Knowledge Sharing and Acquisition in Organizations. Review of Business Research, 7(5).

Hislop, Donald. (2009). Organizational Culture and Knowledge Management ( $3^{\text {rd }}$ ed.). Oxford University Press, USA.

Keyton, Joann. (2011). Communication and Organizational Culture: A Key to Understanding Work Experiences, ( $2^{\text {nd }}$ ed.). Sage Publishing Inc.

Nonaka, I. (1994). A Dynamic Theory of Organizational Knowledge Creation. Organizational Science, 5(1), 14-37. http://dx.doi.org/10.1287/orsc.5.1.14

Nonaka, I., \& Takeuchi, H. (1995). The Knowledge-Creating Company. Oxford University Press.

Nonaka, I., Takeuchi, H., \& Umemoto, K. (1996). The Theory of Organizational Knowledge Creation. International Journal of Technology Management, 11(7)/8, 833-845.

O’Dell, Calra, \& Hubert, Cindy. (2011). The New Edge in Knowledge: How Knowledge Management Is Changing the Way We Do Business ( $1^{\text {st }}$ ed.). Wiley.

Park, H., Ribiere, V., \& Schulte, W. (2004). Critical Attributes of Organizational Culture that Promote Knowledge Management Implementation Success. Journal of Knowledge Management, 8(3), 106-117. http://dx.doi.org/10.1108/13673270410541079

Pasher, Edna, \& Ronen, Tuvya. (2011). The Complete Guide to Knowledge Management: A Strategic Plan to Leverage Your Company's Intellectual Capital ( $1^{\text {st }}$ ed.). Wiley.

Rhoades, Ann, Covey, R. Stephen, \& Stepherdson, Nency. (2011). Built on Values. Creating an Enviable Culture that Outperforms the Competition ( $1^{\text {st }}$ ed.). Jossey-Bass.

Serrat, Olivier. (2012). Knowledge as Culture, ADB. Retrieved from $\mathrm{http}: / /$ digitalcommons.ilr.cornell.edu/cgi/viewcontent.cgi?article=1223\&context=intl

Sternberg, Robert J., \& Horvath, Joseph, A. (1999). Tacit Knowledge in Professional Practice: Researcher and Practitioner Perspectivest ( $1^{\text {st }}$ ed.). Psychology Press.

Wellman, J. L. (2009). Organizational Learning. Palgrave Macmillian. http://dx.doi.org/10.1057/9780230621541

Westover, Jonathan H. (2011). Organizational Culture, Learning, and Knowledge Management. Common Ground Publishing.

Zheng, W., Yang, B., \& McLean, G.N. (2010). Linking Organizational Culture, Structure, Strategy, and Organizational Effectiveness: Mediating Role of Knowledge Management. Journal of Business Research, 63(7), 763-771. http://dx.doi.org/10.1016/j.jbusres.2009.06.005 